\title{
O PAPEL SANITÁRIO DAS REZADEIRAS BRASILEIRAS OUTRORA E AGORA: RESSIGNIFICAÇÕES E CONTINUIDADES
}

\author{
THE HEALTHY ROLE OF BRAZILIAN FEMALE FOLK HEALERS FROM THE PAST \\ AND FROM THE PRESENT: RESIGNIFICATIONS AND CONTINUITIES
}

\author{
EL PAPEL SANITÁRIO DE LAS CURANDERAS BRASILEÑAS DE ANTAÑO Y DEL \\ PRESENTE: RESIGNIFICACIONES Y CONTINUIDADES
}

\author{
Yls Rabelo Câmara \\ Doutora em Filología Inglesa, Universidad de Santiago de Compostela (USC) \\ Universidade Estadual do Ceará (Uece) \\ Fortaleza, Ceará - Brasi \\ ylscamara@hotmail.com \\ Dia Machado Fiuza Fialho \\ Doutora em Educação Brasileira, Universidade Federal do Ceará (UFC) \\ Universidade Estadual do Ceará (Uece) \\ Fortaleza, Ceará - Brasil \\ lia.fialho@uece.br
}

Resumo: Esse levantamento bibliográfico nasceu de nossa inquietação no pós-doutorado quanto ao estudo da importância das rezadeiras brasileiras no passado e no presente. Sua gênese em terras brasileiras deu-se no início da colonização do Brasil, quando para cá rumaram suas antecessoras juntamente com bandeirantes, degredados, físicos, barbeiros e parteiras. Mesclando seus saberes ao dos autóctones e, posteriormente, ao dos escravos africanos que para aqui foram traficados, essas provedoras populares de cura têm-se mantido operantes até os dias correntes, driblando as várias perseguições que vêm sofrendo ao longo desses cinco séculos, ressignificando seu papel e adaptando-se à realidade de seus contextos. Para embasar nossas colocações nesse artigo, fundamentamo-nos em teóricos basilares da área como Câmara, Sanz-Mingo e Câmara (2016), Conceição (2008), Rosario et al. (2014), Stancik (2009) e Theotonio (2011) - para citar alguns. Concluímos que mais de quinhentos anos após sua chegada em terras brasileiras, as rezadeiras têm se mantido como uma referência de provisão de saúde em níveis físico, mental, espiritual e social; foram e são imprescindíveis no passado e no presente; serão necessárias, seguramente, no futuro e por isso sua repaginação constante tem sido de fundamental importância para a sua continuidade.

Palavras-chave: medicina popular; repaginação; rezadeiras brasileiras.

Abstract: This bibliographic survey comes from our postdoctoral concern about the importance of Brazilian folk healers in the past and in the present time. Their genesis in Brazilian lands occurred at the beginning of the colonization of the country, when their ancestors came here along with bandeirantes, outlaws, physicists, barbers and midwives. Mixing their knowledge with that of the indigenous, and later with that of the African slaves, those popular healers have remained operative up to the present day, overcoming the various persecutions they have been suffering throughout those five centuries, reframing their role and adapting themselves to the reality of their contexts. In order to base our positions on this article, we base ourselves on theorists of the area such as: Câmara, Sanz-Mingo and Câmara (2016), Conceição (2008), Rosario et al. (2014), Stancik (2009) and Theotonio (2011) - to cite some. We conclude that more than five hundred years after their arrival in Brazilian lands, female folk healers have maintained themselves as a reference of health provision in physical, mental, spiritual and social levels; they have been indispensable so far and will surely be necessary in the future.

Keywords: female brazilian folk healers; popular medicine; redesign.

Resumen: Esta revisión bibliográfica nació de nuestra preocupación postdoctoral por el estudio de la importancia de las curanderas brasileñas en el pasado y en el presente. Su génesis en tierras brasileñas tuvo lugar al inicio de la colonización de Brasil, cuando sus antecesoras se trasladaron aquí junto con bandeirantes, exiliados, físicos, barberos y parteras. Fusionando su conocimiento con el de los nativos y, posteriormente, con el de los esclavos africanos que aquí fueron traficados, estas proveedoras populares de curaciones han permanecido en funcionamiento hasta la actualidad, esquivando las diversas persecuciones que han sufrido a lo largo de estos cinco siglos, redefiniendo su papel y adaptándose a la realidad de sus contextos. Para respaldar nuestras afirmaciones en este artículo, nos basamos en teóricos fundamentales en el campo como Câmara, Sanz-Mingo y Câmara (2016), Conceição (2008), Rosario et al. (2014), Stancik (2009) y Theotonio (2011), por nombrar algunos. Concluimos que más de quinientos años después de su llegada a tierras brasileñas, las curanderas se han mantenido como un referente para la provisión de salud a nivel físico, mental, espiritual y social; fueron y son esenciales en el pasado y en el presente; Ciertamente serán necesarias en el futuro y por eso su constante repaginación ha sido de fundamental importancia para su continuidad.

Palabras-clave: curanderas brasileñas; medicina popular; repaginación

Para citar - (ABNT NBR 6023:2018)

CÂMARA, Yls Rabelo; FIUZA FIALHO, Lia Machado. O papel sanitário das rezadeiras brasileiras outrora e agora: ressignificações e continuidades. Eccos - Revista Científica, São Paulo, n. 59, p. 1-19, e14185, out./dez. 2021. Disponível em: https://doi.org/10.5585/eccos.n59.14185. 


\section{Considerações iniciais}

A Medicina Popular ${ }^{1}$ no Brasil é um mosaico sincrético de influências religiosas múltiplas onde atuaram e atuam diversos agentes de cura como rezadeiras, parteiras, curandeiras, benzedeiras, mezinheiras, raizeiras, dentistas e sangradores. Quase todos eles estão entre nós desde que éramos colônia de Portugal e seguem conosco como provedores da saúde e bem-estar a seus consulentes, principalmente em rincões mais afastados dos grandes centros urbanos e menos tocados pela vascularização promovida pelo Sistema Único de Saúde (doravante, SUS) e outros organismos sanitários.

Este artigo é resultante de nossa pesquisa pós-doutoral, que se debruçou, entre 2017 e 2018, sobre o estudo das rezadeiras - também denominadas curandeiras e benzedeiras - no município de Fortaleza, capital do estado do Ceará. Sua atuação, especialmente junto a comunidades mais desprovidas de meios econômicos, tem sido de inestimável valia, ainda que venham sofrendo perseguições mais ou menos empedernidas em diferentes momentos e em diferentes contextos de nossa história.

Mesmo assim, ressignificando constantemente seu papel social de benfeitoras populares, reinventando-se para não sucumbirem à hegemonia médico-centrada e à dilapidação de sua imagem pelo cristianismo, mormente, essas mulheres seguem com seu labor de amainar dores, prover saúde e oferecer conselhos e alento, sendo respeitadas em suas comunidades como mulheres especialmente tocadas pela Espiritualidade.

Com o intuito de evidenciarmos sua atuação junto à Medicina Popular, dividimos esse levantamento bibliográfico em três sessões específicas, a saber: na primeira, tratamos de suas origens em terras coloniais brasileiras, advindas que foram da Península Ibérica; na segunda, analisamos sua presença no atual contexto sanitário brasileiro, enquadrando-se em novas práticas terapêuticas, ressignificando sua atuação e resistindo à passagem dos séculos; na terceira, apresentamos seus conhecimentos empíricos alinhados com a Biomedicina e o saber científico, harmonizados pela aplicação prática da ecologia de saberes e pelo que defendem Santos (2018) e Freire (1987).

\footnotetext{
${ }^{1}$ A medicina popular ou rústica é a utilização pelo povo de drogas, substâncias, gestos ou palavras para obter mais saúde para as pessoas. Não é apenas uma coleção de plantas medicinais, usadas para prevenir e curar doenças. Há também o seu lado mágico, suas ações e orações que o povo utiliza na cura dos seus males físicos e mentais. Disponível em: http://basilio.fundaj.gov.br/pesquisaescolar/index.php?option=com_content\&view=article\&id=732. Último acesso em: $28 / 09 / 2021$.
} 


\section{A origem de nossas rezadeiras - da península ibérica à colônia portuguesa na América do Sul}

Conforme Morais (2007), o dom da cura é outorgado às curandeiras logo em seu nascimento: "O dom natural, com poder, precisamente por acontecer à nascença, favorece às criaturas de aptidões especiais que, quando necessário, agem sobre outrem sob o olhar do poder divino - este é de longe o dom mais raro e exclusivo das mulheres.”. (MORAIS, 2007, p. 485). Pelo exposto, evidencia-se também que ele é uma prerrogativa do elemento feminino - assertiva que encontra eco em outros teóricos exponenciais como Paradiso (2011), Stancik (2009) e Zordan (2005).

Em Portugal, conforme Câmara (2020), nossas antigas rezadeiras, santeiras ou saludadoras eram conhecidas também como cuspideiras pelo fato de que se utilizavam de sua saliva nos rituais de cura - mais precisamente a primeira do dia, estando a rezadeira ainda em jejum desde a noite anterior - o que garantia a pureza do material. Além das sessões de benzimento e de aconselhamento, elas preparavam remédios assim como defumações e poções mágicas/feitiços/vomitórios em forma de garrafadas para seus consulentes (MORAIS, 2007).

Já na Galiza, comunidade autônoma espanhola sita à região noroeste da Espanha, justamente em cima de Portugal, essas mulheres especiais, que fazem da cura seu ofício, são relacionadas até hoje às meigas - bruxas benéficas e protetoras, pertencentes ao folclore galego, de acordo com o que Câmara (2020) expõe em um artigo onde defende a importância desta personagem tanto em tempos pretéritos quanto em tempos atuais, ainda que repaginada e ressignificada quanto ao seu caráter.

É interessante ressaltarmos que a Galiza se distingue de outras regiões peninsulares ibéricas porque, segundo Nogueira (1992), ali se processaram e condenaram poucas bruxas na Inquisição e na Caça às Bruxas. Contudo, legaram-se ao inconsciente coletivo galego inúmeras lendas e superstições envolvendo-as diretamente: 
As bruxas são as «sábias» ou «lumias» (lâmias?) ou mais frequentemente «meigas» um possível cruzamento etimológico entre mágica e medicina. Há que se levar em conta também uma extraordinária diferença existente na Galícia entre o litoral e o interior, onde predominavam e predominam superstições muito mais antigas, frente a uma racionalização de crenças no litoral permanentemente em contato com o exterior (em particular com a França). Dentro do país galego, encontram-se, até os nossos dias, figuras que nos remetem a Ovídio e a Apuleyo: as já mencionadas sábias, que podem aparecer como «mencineiras» - a sua designação enquanto curandeira - ou «vedoira», cujo nome traz implícito a capacidade de visualizar o futuro; ou então em seu caráter mais maligno, as «xuxonas», uma chupadora de sangue, ou das vísceras de uma pessoa. «Estria» asturiana ou «lúmia» galega, a primeira menção de que temos notícia desta atividade na Galícia é um processo datado de 1602, onde Constanza do Pazo foi denunciada por três mulheres que diziam que era «bruja», «hechicera», e que «chupaba los niños». Neste último caso, nos encontramos em presença de «lâmias», ou seja, os demónios femininos da mitologia grecoromana, que sedentas de sangue, atacavam os seres humanos, em especial as crianças, e às quais eram atribuídos todos os males sucedidos às mesmas. Personagem sobrevivente de crenças mais remotas e adaptado às cores locais - as «lumias». (NOGUEIRA, 1992, p. 18-19).

Não obstante, infelizmente, informações mais detalhadas sobre elas não se conservaram como se deveria:

\begin{abstract}
Non temos noticias de nomes de mulleres coñecedoras das herbas as súas propiedades, e da súa aplicación nas enfermidades, pero é ben seguro que as houbo xa que moitas delas transmitiron o seu saber a súas descendentes e moitas delas hoxe seguen exercendo esta medicina popular. A dificultade da Muller para acceder a estudos tal como xa mencionabamos anteriormente e as persecucións que sufriron as curandeiras por parte da Inquisición e probablemente unha das causas de que non se atopen escritos que se refiran a elas² ${ }^{2}$ (FERNÁNDEZ-GARCÍA, 2015, p. 102).
\end{abstract}

Entre lâmias, lumias, meigas, magas e bruxas, situamos a benzedeira galega - referência inconteste do poder feminino de cura na Galiza, de onde emigraram para a América do Sul, especialmente para o Brasil e para a Argentina, espanhóis famintos no final do século XIX, advindos de uma Espanha majoritariamente agrária e economicamente atrasada. Antes deles, outros europeus já haviam desembarcado aqui, em diferentes momentos de nossa história, mas especialmente na época da colônia, estabelecendo-se ou retirando-se segundo a resistência por parte dos nativos ou a ausência dela e segundo também os seus interesses e a oportunidade de aqui ficar ou daqui partir.

Em se tratando de Brasil Colônia, aparte dos físicos ibéricos (médicos diplomados), que emigraram para cá na condição de degredados, e dos pajés autóctones, haviam aqui outros agentes populares de cura, também emigrados da Península Ibérica: curandeiros, parteiras, sangradores, dentistas e barbeiros - cujas práticas sobreviveram durante o período monárquico e adentraram no período republicano (STANCIK, 2009). Reiteramos que, naquele momento,

\footnotetext{
${ }^{2}$ Não temos notícias de nomes de mulheres conhecedoras das propriedades das ervas e de sua aplicação em doenças, mas é certo que existiram, uma vez que muitas delas transmitiram seu saber a suas descendentes e muitas delas hoje seguem exercendo essa medicina popular. A dificuldade da mulher para ter acesso a estudos, tal como já mencionamos anteriormente, e as perseguições que as curandeiras sofreram pela Inquisição são, provavelmente, umas das causas pelas quais não se encontrem escritos que se refiram a elas (Tradução nossa do galego para o português).
} 
Medicina, religião e magia pertenciam à mesma egrégora curativa no imaginário popular (RIBEIRO, 2015) e não se diferenciavam claramente uma das outras. Essa é uma realidade ainda presente entre nós.

As doenças tropicais, desconhecidas pelo europeu colonizador, representaram um sólido problema quando a colônia foi oficialmente estabelecida. Em uma época de muitos homens e poucas mulheres, adoecer e/ou parir na Terra Brasilis supunha para essas a morte ou quase isto. Para além disso, somado ao fato de haver poucos físicos para atender à demanda de bandeirantes, evangelizadores e degredados, havia também o pudor feminino, que impedia que os profissionais da saúde exercessem seu labor junto às mulheres, tal como o faziam com os homens.

Para atendê-las haviam as parteiras e as rezadeiras, muitas delas vindas nas caravelas portuguesas na condição de expatriadas por haverem cometido crimes em solo português ou por haverem sido condenadas como bruxas pela Inquisição tardia que ocorrera em Portugal e que durou de 1536 a 1821, como afirma Stancik (2009). Essa mescla de mulheres ibéricas condenadas por bruxaria e párias sociais que para a colônia portuguesa vieram na condição de exiladas são, em suma, as antecessoras de nossas rezadeiras. É oportuno mencionarmos que tanto a Espanha como Portugal $^{3}$ seguem mantendo rezadeiras entre seus agentes provedores de cura, especialmente nas vilas e aldeias onde nem o Estado de Bem-Estar Social, com toda a sua estrutura muito bem-organizada, consegue penetrar com eficiência.

Aos saberes ancestrais e empíricos dessas sábias vetustas, bruxas ou não, que aqui chegaram castigadas com o degredo, juntaram-se os saberes dos indígenas brasileiros autóctones e ao dos escravizados africanos que para aqui foram trazidos entre 1530 e o final do século XIX. Esses conhecimentos, mesclados e reconfigurados, foram arduamente perseguidos em distintos momentos históricos em nosso país. Inseridos em um ambiente onde os médicos diplomados rareavam, nossos antepassados acostumaram-se a procurar outros provedores de cura; dentre eles, as rezadeiras:

\footnotetext{
A ausência de profissionais formados nas academias, em diversas regiões do país, ao longo dos séculos XVIII e XIX, não poderia ser sentida como lacuna por parte da população ou como algo que deveria ser preenchido para o bem geral da comunidade. A população estava habituada a lidar com a inexistência deste profissional. Esta era a regra e essa experiência não era vivenciada necessariamente como falta por parte da população. (FIGUEIREDO, 2005, p. 62).
}

Adentrando mais no tema e centralizando o escopo de nossa investigação no presente, podemos dizer, em linhas gerais, que, à luz de Câmara, Mingo e Câmara (2016), as benzedeiras

\footnotetext{
${ }^{3}$ Especialmente no norte de Portugal, na região de Trás-os-Montes, segundo Câmara (2020).
} 
brasileiras são mulheres que normalmente se dedicam ao lar e, por isso, o mais das vezes, não são economicamente ativas. Normalmente prescindem de uma agenda e atendem seus consulentes conforme estes as procuram por demanda espontânea (CONCEIÇÃO, 2008). A varanda, o jardim e o quintal são os espaços da casa onde costumeiramente realizam seu trabalho, que é também de onde recolhem as folhas e os ramos das plantas que serão utilizados nas rezas. Quanto a estes acessórios, Santos (2009) expõe que:

\begin{abstract}
Para compor este ritual de cura, as rezadeiras podem utilizar vários elementos acessórios, dentre eles: ramos verdes, gestos em cruz feitos com a mão direita, agulha, linha e pano, além do conjunto de rezas. Estas podem ser executadas na presença do cliente, ou à distância. Em seu ofício, de amplo reconhecimento, essas mulheres "rezam" os males de pessoas, animais e plantas, bastando apenas que alguém diga os seus nomes e onde moram. (SANTOS, 2009, p. 12-13).
\end{abstract}

Segundo Câmara, Sanz-Mingo e Câmara (2016), caracterizam-se por serem mulheres pobres e enxergadas como sujeitos históricos que não possuem letramento suficiente. São necessariamente iniciadas e, em sua grande maioria, herdam o poder de cura e o conhecimento acerca dos mistérios de suas práticas por meio de um rezador, apesar de que algumas fogem a essa regra. Para Halbwachs (1990), as rezadeiras são sujeitos que preservam a memória e a oralidade e que contribuem para com a identidade social que seu coletivo representa - por essa e outras razões, o registro delas, de seus discursos e de suas práticas é tão importante para que não percamos o legado que nos têm deixado.

Pelo levantamento bibliográfico que fizemos e pela coleta de dados in loco, por meio de observações participantes para trabalhos afins nessa mesma temática, acreditamos que o porquê da procura por essas mulheres não repousa somente na carência de médicos em algumas regiões mais pobres de nosso país, onde elas se encontram em maior número e à luz do que ocorre com Espanha e Portugal, como mencionamos acima, mas também se deve ao fato de que elas estão mais próximas de seus consulentes do que os médicos o estão de seus pacientes e porque as benzedeiras curam as doenças que os médicos não diagnosticam nem curam - como o mau olhado, a maior queixa do público que as busca (CÂMARA; SANZ-MINGO; CÂMARA, 2016).

Embora haja rituais de cura de origem ameríndia e africana em seu modus faciendi, o que predomina na benzedura brasileira é o apelo aos santos católicos (ainda que rebatizados com nomes de entidades outras, pertencentes a outros panteões sagrados, como o yorubá). Para Burke (2003, p. 5), em seus estudos acerca do hibridismo cultural, ao nos defrontarmos com o que possivelmente diz respeito a duas tendências culturais distintas, não devemos entendê-las de forma separada, pois “[...] não existe uma fronteira cultural nítida ou firme entre grupos, e 
sim, pelo contrário, um continuum cultural.”. Independentemente da religião que professem, cujas influências estendem-se à sua práxis, a importância destas mulheres em suas comunidades é incontestável:

[...] ainda que o sistema público de atenção à saúde seja um importante e permanente aliado na prevenção e cura de enfermidades, a população brasileira, sobretudo a de camadas de baixa renda, continua fazendo uso de outras opções terapêuticas, tornando vivo o pluralismo médico no país. (ANDRADE; CORREIA, 2008, p. 13).

Sem embargo, essa preferência popular por curandeiras igualmente populares atraiu a perseguição sobre elas. Assim como a pajelança, o cristianismo popular, categoria à qual as rezadeiras invariavelmente pertencem, tem sido acossado pelos médicos e defensores do saber científico; principalmente o foi entre o final do século XIX e o início do século XX, quando o Positivismo estava em voga, à luz dos qual, nossa Biomedicina está ancorada. Para Figueiredo (2005),

Os curandeiros não podiam exercer seu trabalho sem o risco de eventual incômodo policial. A legislação indica que, no decorrer do século XIX, principalmente a partir da segunda metade, havia um controle mais rigoroso para o exercício das atividades relacionadas à saúde. (FIGUEIREDO, 2005, p. 65).

$\mathrm{Na}$ tentativa de evitar o rótulo de charlatãs, grande parte das benzedeiras passou a se assumir como católicas praticantes desde então, embora seus sistemas de crenças fossem e sejam outros, conforme Conceição (2008). Ademais, o fato de não cobrarem por suas rezas e conselhos tem sido uma estratégia amplamente utilizada por elas para evitar a desconfiança alheia sobre o seu labor.

Ratificamos que mesmo contando com um sistema de saúde que pode ir de precário a regular, o paciente que procura o médico, a depender de alguns fatores, tende a não deixar de procurar as benzedeiras quando delas necessita, o que reaproxima a terapêutica alopática da magia (THEOTONIO, 2011). Não raro, pessoas que podem pagar por um bom plano de saúde ainda se voltam para essa manifestação da cultura popular e procuram as benzedeiras para proteção e cura de males de todo tipo (ROSÁRIO et al., 2014). Em resumo: essas práticas não se restringem somente às classes menos favorecidas de meios econômicos e os consulentes, em sua maioria, as identificam como naturais:

\footnotetext{
Não são apenas pessoas "simples", oriundas da classe popular e que tradicionalmente tiveram pouco acesso à educação formal e ao saber médico. Pessoas instruídas, que se consultam frequentemente com médicos e que possuem uma situação financeira mais confortável também o fazem; é o caso de políticos, professores, profissionais da saúde, entre outras. Pessoas que acreditam nas benzedeiras, no poder das rezas, na eficácia das ervas... Pessoas que buscam a medicina popular como alternativa ou como uma forma de complementar o tratamento da medicina tradicional. Afinal, muitas pessoas vão ao médico e à benzedeira ao mesmo tempo. (SANTOS, 2007 apud HOFFMANN-HOROCHOVSKI, 2015, p. 121).
} 
Sobre a mescla de agentes populares de cura (na forma de rezadeiras) com a prática médica alopática hegemônica, visando prover saúde aos brasileiros, tratamos a seguir.

\section{Da biomedicina hospitalocêntrica hegemônica à revalorização das rezadeiras}

Até a década de 1980, o acesso à saúde no Brasil era muito restrito para a população desprovida dos mínimos sociais e estava reservada basicamente a quem podia pagar por serviços médicos às expensas próprias ou através de convênios da contribuição previdenciária do Instituto Nacional de Assistência Médica e Previdência Social - INAMPS. A saúde complementar, por meio de convênios particulares, era ainda um movimento recente na era anterior ao surgimento do SUS e atingia apenas uma pequena parcela de brasileiros.

Ao cidadão pobre, pouco lhe restava de acesso aos serviços sanitários e, quando era possível a eles aceder, era normalmente na condição excludente de indigente, onde o tratamento (desde as condições básicas como alimentação e abrigamento) era diferenciado do dispensado aos contribuintes particulares ou conveniados. O que restava ao sujeito desprovido de recursos financeiros necessários para pagar por serviços de saúde era recorrer à religião, às curandeiras e ao arsenal fitoterápico e fitoenergético por elas prescrito.

O sistema de práticas sanitárias hegemônicas anteriores ao SUS estava consolidado em um modelo médico-centrado e hospitalocêntrico pautado na doença, com atenção máxima aos sinais, sintomas e síndromes apresentados pelos sujeitos. Em termos mundiais e, especificamente nacionais, tal modelo começou gradativamente a sofrer uma importante ruptura devido às reflexões e insatisfações da sociedade civil em relação às formas desumanas às quais os doentes eram submetidos. $\mathrm{O}$ ano de 1978 foi o marco para o surgimento da Reforma Sanitária no Brasil, através do Movimento dos Trabalhadores de Saúde Mental (MTSM), que se organizaram em assembleias que resultaram em Conferências Nacionais de Saúde.

Especificamente a III Conferência Nacional de Saúde deu base para a Seção Saúde da Constituição de 1988 e, consequentemente, para o SUS - sistema complexo e articulador nacional de ações e serviços de saúde nas esferas municipal, estadual e federal, integrante do sistema brasileiro de Seguridade Social e que surgiu pela necessidade de rompimento do movimento sanitário vigente na época, a fim de prover uma concepção ampliada de saúde que pudesse oferecer bem-estar ao usuário pela assistência integralizada nas mais diversas dimensões (física, psicológica, social, espiritual e ecológica), conforme Vasconcelos e Pasche (2003). 
Segundo Amarante (2003) e Paim (2003), com o surgimento do SUS, pela primeira vez na história do Brasil, a saúde passou a ser um direito universal, descentralizado, integralizado, equitativo e hierárquico; com direito não apenas à informação para o usuário, mas também à participação paritária entre sociedade civil e sociedade política. Teve como marco jurídiconormativo a Carta Magna de 1988 e as leis $\mathrm{N}^{\circ} 8.080 / 90$ e $\mathrm{N}^{\mathrm{o}}$ 8.142/90, estipulando a obrigação do Estado em prover acesso aos serviços de saúde para todos os cidadãos.

Consoante Merhy (1997), com o SUS, o modelo sanitário hospitalocêntrico, prescritivo e médico-centrado foi perdendo espaço para a gradativa implantação do modelo assistencial multiprofissional, focado na construção de tecnologias de gestão que integram o sujeito e as ações humanas através das tecnologias leves de acolhida das demandas subjetivas dos usuários. De acordo com Erdmann et al. (2009), o cuidado é um modo de agir resultante de uma prática direcionada para outrem, plena de aspectos sociais, culturais, históricos e políticos; outrora uma atribuição destinada socialmente às mulheres reservadas ao âmbito doméstico. Contudo, na contemporaneidade, extrapolou para o âmbito público e implica em um repertório de zelo, atenção, comportamento atitudinal de escuta ativa e empática e de responsabilidade para com o Outro.

A tecnologia das relações, campo das tecnologias leves, de acordo com Cecílio (1997), supõe a dimensão dialógica, per se fortalecedora do vínculo e da troca de saberes entre trabalhadores e usuários e seus familiares, assim como de laços afetivos, integrais e resolutivos, visando a satisfação dos usuários e a singularidade do sujeito adoecido (ou não) e todo o seu potencial de saúde no contexto da clínica ampliada, conforme Merhy (2004) e Coimbra (2003). Em resumidas palavras, uma das relevâncias do SUS, segundo Carvalho e Cunha (2006), é a de pensar a gestão das práticas de saúde sob a perspectiva dialógica, consolidada pela presença de equipes multidisciplinares humanizadas, capazes de prover tecnologias leves de acolhida integralizada ao sujeito a partir da expressão da comunicação, do acolhimento, do fortalecimento da autonomia e das relações de vínculo.

Apesar de tantos avanços no cuidado propiciado pelo SUS, atender à grande demanda populacional e à perpétua falta de recursos públicos suficientes para o provimento da saúde coletiva provocaram problemas para com sua efetivação, resultando, muitas vezes, em práticas e recursos pobres de saúde para a população economicamente desprovida, com descaso para com a gravidade dos casos; com maus atendimentos feitos em curto espaço de tempo; com falta de medicações, desde as mais básicas; com as longas filas de espera para atendimentos; com internações e procedimentos cirúrgicos que acabam, muitas vezes, provocando a mistanásia. De acordo com Silva (2021, p. 32): 
O resgaste das práticas de medicina popular como instrumento de saúde pública, no caso das benzedeiras [...] integrado à lógica da especialidade medicina de família e comunidade, efetivada no Nordeste brasileiro e presente na atenção primária à saúde, faz-se como porta de entrada para o Sistema Único de Saúde.

O ser humano, por sua condição gregária, necessita do contato interpessoal, da acolhida de suas dores e da esperança para o desalento das circunstâncias adversas. Segundo Buber (1979), é no contexto relacional e dialógico que essa realidade pode ser alcançada. A relação dialógica é possível no "entre" das relações interpessoais que possibilitam a atualização de si e a ultrapassagem do próprio Eu, sem que se perca em si mesmo. Por sermos seres de relação, muitas vezes a boa acolhida sobrepõe-se à técnica excepcional porque, para Buber (1979), muito mais do que falar com o Outro, a relação dialógica permite a plenitude da relação Eu-tu.

Para esse teórico, a atualização de si na relação com o Outro está diretamente relacionada com a capacidade real de haver um processo de ouvir autêntico, devotando ao sujeito interesse generoso e autêntico por suas queixas, atenção e doação amorosa de tempo e o cuidado necessário de fazer com que o consulente se torne presente. É, para Freire (1987, p. 78-79), um exercício dialógico entre as pessoas na construção de um saber pautado em significados comuns: “O diálogo é este encontro dos homens, mediatizados pelo mundo, para pronunciá-lo [...], o diálogo se impõe como caminho pelo qual os homens ganham significação enquanto homens.".

Essa relação mais próxima e dialógica deu-se também com o surgimento de dois programas que, por um lado, se aproximaram mais dos usuários, e por outro, “[...] iniciaram o processo de consolidação da descentralização de recursos no âmbito do SUS, através da Norma Operacional Básica - NOB-SUS 1/96, publicada em 6 de novembro de 1996” (LIMA, 2019, p. 21): o Programa dos Agentes Comunitários de Saúde (PACS) e o Programa Saúde da Família (PSF).

Paralelamente a isso, de acordo com o movimento de rejeição às relações interpessoais frágeis, ao consumismo, ao automatismo e ao individualismo exacerbado, nascido na contracultura há mais de meio século, uma nova demanda social vem gradativamente surgindo: a do retorno às origens do cuidado, à busca de estratégias preventivas de saúde e às vivências ecológicas. Diante desse fenômeno social, no ano de 2006, foi criada a Política Nacional de Práticas Integrativas e Complementares (PNPIC - MS Portaria $n^{\circ}$ 971-2006) visando a busca ativa de melhores práticas para o trabalho nos serviços públicos de saúde diante do cenário deficitário de recursos materiais e humanos supra exposto. 
As Terapias Integrativas e Complementares consistem em um campo de estratégias multidisciplinares que visam atender às demandas dos sujeitos em sua inteireza, ou seja, de forma holística, objetivando a prevenção de doenças e a promoção da saúde através de tecnologias não invasivas e quase sempre de baixo custo. Quando as doenças físicas, mentais ou espirituais já existem, as Terapias Integrativas e Complementares assumem a função de prover equilíbrio, bem-estar e tomada de consciência e de responsabilidade para com o autocuidado.

Avançando-se nessa egrégora, no ano de 2017, de acordo com a Portaria MS No 145/ 2017, o SUS legitimou a inserção das seguintes práticas: plantas medicinais, quiropraxia, reflexologia, termalismo/crenoterapia, acupuntura (Medicina Tradicional Chinesa), arteterapia, auriculoterapia, ayurveda, biodança, dança circular, fitoterapia, automassagem, Medicina Antroposófica, meditação, homeopatia, massagem fitoterapia, terapia comunitária integrativa, Reiki, shantala e yoga.

Com essa implantação, abriu-se também um horizonte de possibilidades para que as curandeiras, de posse desses saberes, ressignificassem sua presença no cenário sanitário em transformação em nosso país e se apropriassem, cada vez mais, da importância de sua presença nele. A partir de então, um novo caminho tem-se estendido para elas e para outros atores sociais que trabalham com a sanação por meios distintos da lógica hospitalocêntrica e médico-centrada e cujo saberes ancestrais são ligados à oralidade e à natureza, saberes também conhecidos como Epistemologias da Floresta. Contudo, há que se considerar que nenhum desses saberes - quer empírico quer científico - anula o outro; ao contrário: complementam-se. É o que apresentamos a seguir.

\section{A ecologia de saberes - a homeostase dos conhecimentos em paralelo}

Conforme Batista (2020), as reiteradas tentativas do Estado para promover a valorização das medicinas tradicionais de maneira alternativa e complementar à Biomedicina, via de regra, polarizam, problematizam e polemizam a questão, criando tensão e colocando saberes em conflito quando, na verdade, como afirma Freire (1987, p. 68): “[...] não há saber mais nem saber menos, há saberes diferentes.”.

Ao tentar invisibilizar saberes vetustos, transmitidos geracionalmente por meio da oralidade e da práxis de homens, mas, principalmente, de mulheres especialmente tocadas pela Espiritualidade no que se refere ao dom da cura, a medicina convencional atua "[...] de forma fragmentada, mecanicista, especializada e biológica, sendo estes os principais aspectos que são 
considerados no processo de cura.”. (BATISTA, 2020, p. 53). Essa forma hegemônica de prover saúde, calcada em ideias positivistas e cartesianas engessadas, dirige seu olhar para a doença muito mais do que para o doente, segundo Silva (2021), e não é capaz, sozinha, de resolver as demandas do nosso povo quanto ao tema sanitário.

Diferentemente dos médicos, que são mais centrados nos problemas pontuais que seus pacientes lhes trazem ao consultório - frequentemente consolidados em doenças, sintomas e mal-estares que são averiguados no pouco tempo que dispõem nas consultas e que são melhor explorados nos exames clínicos, se possíveis de serem realizados - as rezadeiras costumam enxergar seus consulentes holisticamente e para muito além dos sintomas postos acima. Destarte, consideram fatores biológicos unidos aos espirituais e ambientais nos consulentes que as buscam, nas tentativas normalmente frutíferas de gerar um diagnóstico, pois acreditam que uns aspectos interferem nos outros e que para curar uma pessoa do mal que a está incomodando, precisam ampliar o raio de ação de sua benzedura para outras esferas que a contemplam que não seja apenas a física.

Portanto, as doenças, tais como as concebemos, estão ligadas a processos multifatoriais que nenhum saber, por mais prestigioso que seja para uma dada comunidade, consegue debelar ou resolver de forma singular e/ou absoluta. Por esta e outras razões, Edgar Morin defende que estes dois saberes - o empírico e o científico - são imprescindíveis e inseparáveis: “[...] podem por vezes confundir-se, mas sempre provisoriamente. Toda renúncia ao conhecimento empírico/técnico/racional conduziria os humanos à morte, toda a renúncia às suas crenças fundamentais desintegraria a sua sociedade" (MORIN,1996, p. 144).

Neste trabalho, até pelo caráter que apresenta, enaltecendo o labor das rezadeiras, valoramos as pautas defendidas pelas Epistemologias do Sul, desenvolvidas por Boaventura de Sousa Santos (2010), que validam os conhecimentos produzidos pela perspectiva dos que foram vítimas das violências, opressões, dominações, exclusões e injustiças causadas pelo capitalismo, pelo colonialismo e pelo patriarcado - esse tripé que vem atentando contra o saber das rezadeiras e tentando amordaçá-lo sem consegui-lo, mas que indubitavelmente o subalternizou e, até certo ponto, o inviabilizou de maneira muito expressa e o silenciou em muitos momentos. Evidentemente, conforme aponta Lima (2019), esse "Sul” não é geográfico, mas geopolítico:

É muito importante termos em mente que a ciência moderna não é o único conhecimento válido, e que existem alternativas e outros conhecimentos que se somem a ela. É preciso desconstruir esse conceito de validade única imposto pela política do conhecimento eurocêntrico. (LIMA, 2019, p. 40). 
Nesse sentido, a sociologia das ausências que Santos (2018) defende, dialoga com a ecologia de saberes, tendo por base o combate à monocultura do saber, provando que não existe nem um saber geral e nem uma ignorância geral, uma vez que, à luz de Lima (2019), ela é impulsionada pela busca da diversidade de conhecimentos, seja dentro da seara científica ou da não científica; seja do conhecimento ocidental ou do oriental. Essas práticas de saber não têm porque serem exclusivamente linguísticas e devem incluir outros tipos de expressão e de comunicação, convocando para uma epistemologia polifônica e prismática que deve ser exercida pela busca de convergências entre saberes múltiplos.

Ou seja: a possibilidade de diálogo e a disputa epistemológica entre saberes diferentes acontece especialmente ao se substituir a monocultura do saber científico por uma ecologia de saberes, que permite não apenas superar a essa monocultura do saber científico, mas também a ideia de que os saberes não científicos são a ele (SANTOS, 2018). Ao que Lima (2019, p. 47) complementa: "A lógica da monocultura do saber e do rigor da Biomedicina precisa ser confrontada com a identificação de outros saberes e de outros parâmetros de rigor que operam credivelmente nas práticas de saúde".

Sendo assim, Santos (2018) assevera que a ecologia de saberes considera a interculturalidade também como interconhecimento, remetendo-nos à percepção de que as diferentes formas de saberes são igualmente importantes, pois ao passo que são diferentes, como já mencionamos anteriormente, são também complementares uns aos outros. Não disputam o espaço; convivem em harmonia; não são opositores e nem subalternos, mas aros de uma mesma corrente e que juntos podem configurar uma nova forma de pensar e de agir sobre uma determinada realidade.

Ainda conforme Santos (2018), as práticas de saber dominantes, fundamentadas na Ciência moderna ocidental, produzem e reproduzem a desigualdade social no mundo. Como não está distribuída equitativamente no planeta, nem como sistema de produção nem como sistema de consumo, as desigualdades no acesso, controle e uso da Ciência são o resultado de desigualdades sociais e reforçam-nas. A ecologia de saberes não somente admite muitas formas de saberes, como parte da dignidade e validade epistemológica de todos eles, que deve ser pautada no princípio da precaução, ou seja, deve-se preferir a forma de conhecimento que garanta a maior participação de grupos sociais envolvidos na concepção, execução, controle e intervenção no mundo e isso se estende à Saúde (SANTOS, 2018).

É próprio desta metodologia averiguar em que medida a ausência de outros saberes - a já citada sociologia das ausências - é o resultado de uma ocultação produzida pela 
epistemologia que consagra o conhecimento científico hegemônico como único: “[...] na ecologia de saberes a vontade é guiada por várias bússolas com múltiplas orientações; não há critérios absolutos nem monopólios de vontade; cada saber é portador da sua epistemologia pessoal.”. (SANTOS, 2018, p. 67). Portanto, não é possível seguir uma única rota quanto a esse sentido. Deve-se avaliar a possível contribuição de cada saber em diferentes áreas, ou momentos ou para diferentes objetivos.

Portanto, no que concerne à atuação e às trocas cotidianas das rezadeiras com as comunidades nas quais estão inseridas, sendo conhecedoras de uma gama imensurável de saberes empíricos, pode haver a tessitura de várias possibilidades de construção de outras epistemologias, mais emancipatórias, através de uma sistematização complexa, singular e plural dos saberes sobre a saúde das populações (LIMA, 2019).

Muito se discute acerca da influência das representações sociais hegemônicas sobre a doença e o doente, expondo os processos de "hiperespecialização" e "cientificidade", que o campo da saúde tem sustentado e que muitas vezes gera conflitos entre profissionais e usuários, pelos domínios do "corpo". Assim, sustenta-se a existência de um permanente confronto entre a lógica biomédica e a leiga no que diz respeito às questões sanitárias. Uma das formas de minimizar essa tensão seria por meio da pedagogia dialógica proposta por Paulo Freire, com a finalidade de resgatar os sentidos e lógicas internas da população sobre esse campo, para permitir que o conhecimento leigo amplie o profissional.

Na proposta de Freire há uma semelhança com a ecologia de saberes de Boaventura Santos, considerando as modalidades de pensamento e de ações criadoras de conhecimento, sentido e significado como formas legítimas de se conhecer e se lidar com o mundo. $\mathrm{O}$ isolamento dos conhecimentos ancestrais remete ao pensamento de Santos (2018) sobre a linha abissal e a sociologia das ausências, e ajuda a compreender formas de exclusão que desconsideram saberes, tradições, culturas e práticas de saúde. A negação é essencial à constituição da ciência biomédica; condição para afirmar a sua universalidade e validade única. Porém, a ecologia de saberes é mais crítica ao modelo dominante e mais ampla, por estar associada a uma compreensão ampliada.

Como se pode supor e constatar, o campo das interações práticas da ecologia de saberes não é na Universidade, não é na Academia; considera-se como seu lugar de enunciação todo aquele no qual os saberes são convocados e geram experiências que transformam, como ocorre com as rezadeiras e outros agentes populares de cura, por exemplo. A forma como essas mulheres viabilizam a saúde para quem as busca com a intenção de mantê-la, restabelecê-la ou recuperá-la é diametralmente oposta à forma como as políticas oficiais de saúde, que se baseiam 
na alopatia, funcionam - o mais das vezes, refletindo uma forma capitalista de medicar, espelhando o desamparo social desses pacientes. Conforme Batista (2020, p. 85),

\begin{abstract}
Os saberes populares relacionados às práticas do cuidado a saúde, são denominadas práticas populares e integrativas do cuidado. Estão presentes por todo território e são perpetuadas por aqueles que entendem que estas práticas ajudam a formar outras novas com relação a estes cuidados. [...] As práticas do cuidado são aquelas desenvolvidas por grupos populares ou locais, que apesar do sistema oficial conseguiram persistir e continuar atuantes junto aos problemas de saúde - aqui entendida como bem-estar tanto do corpo quanto da alma. Tais práticas perpassam desde um benzimento até reparações de danos físicos por meio de intervenções, de forma especial naqueles locais onde as práticas de saúde por parte do Estado são ausentes. As práticas do cuidado estão ligadas ao saber local, vindo de conhecimentos que passam de geração a geração através da oralidade, bem como fazendo uso de recursos oferecidos pelo ambiente no auxílio das atividades de cura.
\end{abstract}

Esses saberes, essas práticas populares ${ }^{4}$ de saúde, ainda segundo Batista (2020), que pareciam estar condenados ao epistemicídio até algum tempo atrás, têm ganhado renovado interesse tanto por parte dos organismos estatais quanto por parte do saber acadêmico, e têm sido considerados aliados das práticas terapêuticas utilizadas no SUS. É neste espaço de relações entre rezadeiras e seus consulentes, muitas vezes aconselhados por elas a buscarem ajuda médica, que a ecologia de saberes se estabelece - porque as rezadeiras sabem da importância de se dialogar com outras práticas terapêuticas, sejam elas alopáticas ou não.

Por isso, as Epistemologias do Sul - em favor de um conhecimento emancipatório, em busca da diversidade de experiências que suscitam a ecologia de saberes - são tão necessárias. Superar a hegemonia do saber biomédico hegemônico implica na promoção de diálogos mais horizontais, permitindo a emergência de saberes e práticas emancipatórios, alternativas para outras formas de saber, trabalhar e produzir em coletividade (SANTOS, 2018).

As rezadeiras, neste contexto em constante transformação, são cada vez mais necessárias. Com seus conhecimentos que transcendem gerações e alcançam outras mulheres no planeta com a mesma vocação para a benzedura - conhecimentos esses que remontam às origens da Humanidade por ancestrais que são, calcados na memória, na oralidade e na transmissibilidade de conhecimentos de maneira geracional - elas imprimem sua marca em sua longa trajetória que nos remete a tempos imemoriais e que, se bem preservada, há de se estender continuamente, ajudando a minorar dores e amainar males nos lugares mais díspares deste nosso imenso Brasil.

\footnotetext{
${ }^{4} \mathrm{O}$ conceito de práticas populares de saúde "[...] compreendem qualquer forma de cura que não seja propriamente biomédica, abrangendo práticas advindas da cultura popular, tais como o benzimento e as ligadas a religiões.". (OLIVEIRA; MORAES, 2010, p. 419).
} 


\section{Considerações finais}

Percebemos o quanto a presença das rezadeiras tem sido necessária, em maior ou menor grau, em diversos episódios de nossa História, nos mais distintos rincões do país e pelas mais diferentes razões. Ameaçadas pelo saber falocêntrico e hospitalocêntrico em variados momentos nesses últimos cinco séculos, elas jamais perderam sua importância curativa junto às comunidades às quais pertencem, atraindo pessoas de todos os estratos sociais em busca de cura física, mental, espiritual e de conselhos para a resolução de problemas de toda ordem.

Mesmo com a implantação do Sistema Único de Saúde, sua atuação jamais foi eclipsada, especialmente após a implantação da Portaria MS No 145/ 2017, que legitima a inserção de novas práticas holísticas como a fitoterapia, que reforça a necessidade de seus conhecimentos empíricos, de sua farmacopeia ancestral. Promover, como elas promovem, a diversidade e a pluralidade para além do capitalismo e da globalização neoliberal, não pressupõe que a ciência moderna seja recusada, mas que seja reconfigurada numa constelação mais ampla de saberes onde coexista com práticas de saberes não científicos e que sobreviveram ao epistemicídio ou que, apesar da invisibilidade epistemológica, têm emergido e florescido nas lutas contra a desigualdade e a discriminação à qual foram levadas, tenham ou não por referência um horizonte não capitalista (SANTOS, 2010).

Com as constantes ressignificações e atualizações dos papéis sociais das rezadeiras, fazse necessário que a Academia volva seu olhar destituído de preconceito para essas mulheres que provêm a cura e que estão presentes nos mais díspares lugares do planeta. No levantamento bibliográfico que fizemos para atualizarmos o estado da arte em nossos estudos sobre elas, no estágio pós-doutoral que realizamos, sentimos uma lacuna quanto a pesquisas mais aprofundadas sobre essas mulheres e acreditamos que esse hiato pode ser preenchido por investigadores que bebam da fonte de nossas mais vetustas e ancestrais raízes culturais.

Desta forma, humildemente desejamos que nossas contribuições neste artigo joguem luz sobre esse tema tão rico e que nos dirige aos nossos primórdios; que tenhamos evidenciado a importância das rezadeiras tanto outrora como agora, apresentando como elas vêm se reconfigurando, ressignificando suas práticas e renovando sua importância validade como agentes de saúde populares em um Brasil que delas ainda muito necessita. 


\section{Referências}

AMARANTE, P. Saúde mental, políticas e instituições: programa de educação à distância. Rio de Janeiro: FIOTEC/FIOCRUZ, EAD/FIOCRUZ, 2003.

ANDRADE, João Tadeu de; CORREIA, Heloise Maria de Riquet. Curadores tradicionais no Ceará: inserção social, perfil terapêutico e contribuição para a saúde pública. Anais da $26^{\mathrm{a}}$ Reunião Brasileira de Antropologia, Porto Seguro, Bahia, Brasil, p. 1-12, jun., 2008.

BATISTA, Edione Rodrigues. Saberes, Crenças e Rezas que Curam: a relação entre quem reza e quem é curado no município de Icapuí/CE. Dissertação (Mestrado). Orientadora: Profa. Dra. Karlla Christine Araújo Souza. 114 f. Programa de Pós-Graduação em Ciências Sociais e Humanas, Universidade do Estado do Rio Grande do Norte, Mossoró, 2020.

BUBER, Martin. Eu e tu. Introdução e tradução de Newton Aquilles Von Zubben. 2 ed. São Paulo: Cortez e Moraes, 1979.

BURKE, Peter. Hibridismo cultural. São Leopoldo: Ed. Unisinos, 2003.

CÂMARA, Yls Rabelo. Das Bruxas, Saludadoras, Santeiras, Cuspideiras e Meigas Europeias às Atuais Rezadeiras Tradicionais Brasileiras. Caminhos, Goiânia, v. 18, n. 2, p. 502-514, 2020.

CÂMARA, Yls Rabelo; SANZ-MINGO, Carlos; CÂMARA, Yzy Maria Rabelo. Das bruxas medievais às benzedeiras atuais: a oralidade como manutenção da memória na arte de curar uma pesquisa exploratória. Boitatá, v. 11, n. 22, p. 221-236, 2016.

CARVALHO, S. R.; CUNHA, G.T. A gestão da atenção na saúde: elementos para se pensar a mudança da organização na saúde. In: CAMPOS, G. W. S; MINAYO, M. C. S; AKERMAN, M.; DRUMOND, J. M.; CARVALHO, Y, M. Tratado de Saúde Coletiva. Rio de Janeiro: Hucitec, Fiocruz, 2006.

COIMBRA, V. C. C. O Acolhimento no Centro de Atenção Psicossocial. 190 f. Dissertação (Mestrado). Orientadora: Profa. Dra. Luciane Prado Kantorski. Mestrado em Enfermagem Psiquiátrica, Escola de Enfermagem de Ribeirão Preto, Universidade de São Paulo, Ribeirão Preto, 2003.

CONCEIÇÃO, Alaíze dos Santos. Ser rezadeira: experiências e práticas culturais de participantes da Medicina popular, Gov. Mangabeira, Recôncavo Sul da Bahia (1950-1970). Revista Fazendo Gênero 8 - Corpo, Violência e Poder, p. 1-7, 2008.

CUNHA, Lidiane Alves da. ASSUNÇÃO, Luiz Carvalho. Abençoada cura: poéticas da voz e saberes de benzedeiras. Revista Brasileira de História das Religiões, v. 9, n. 27, p. 189-227, jan./abr., 2017.

ERDMANN, Alocoque Lorenzini; MELLO, Ana Lúcia Schaefer Ferreira de; ANDRADE, Selma Regina de; KOERICH, Magda Santos; KLOCK, Patricia; NASCIMENTO, Keyla Cristiane do. Sistema de cuidados em enfermagem e saúde: as interações vivenciadas nos grupos de pesquisa. Ciência, Cuidado e Saúde (Online), v. 8, n. 4, p. 675-682, out./dez., 2009. 
FERNÁNDEZ-GARCÍA, Maria Isabel. Os científicos lucenses do século XVIII. Lvcensia, p. 85-102, 2015.

FIGUEIREDO, Betânia Gonçalves. Os manuais de medicina e a circulação do saber médico no século XIX no Brasil: mediação entre o saber acadêmico e o saber popular. Educar, Curitiba, v. 2, n. 25, p. 59-73, 2005.

FREIRE, Paulo. Pedagogia do oprimido. 17 ed. Rio de Janeiro: Paz e Terra, 1987.

HALBWACHS, Maurice. A memória coletiva. São Paulo: Editora Revista dos Tribunais LTDA, 1990.

HOFFMANN-HOROCHOVSKI, Marisete Teresinha. Benzeduras, garrafadas e costuras: considerações sobre a prática da benzeção. Guaju - Revista Brasileira de Desenvolvimento Territorial Sustentável, v.1, n. 2, p. 110-126, jul./dez., 2015.

LIMA, Jane Mary de Miranda. O processo de trabalho dos agentes comunitários de saúde e a vigilância em saúde do trabalhador na perspectiva da ecologia de saberes. 131f. Dissertação (Mestrado em Profissional em Vigilância em Saúde do Trabalhador). Orientadora: Prof. ${ }^{a}$ Dra. Ana Maria Cheble Bahia Braga. Programa de Pós-Graduação em Saúde Pública, Ministério da Saúde, Fundação Oswaldo Cruz, Escola Nacional de Saúde Pública Sergio Arouca, Enesp, Rio de Janeiro, 2019.

MERHY, E. E. O Ato de Cuidar: a Alma dos Serviços de Saúde. In: Brasil. Ministério da Saúde. Secretaria de Gestão do Trabalho e da Educação na Saúde. Departamento de Gestão da Educação na Saúde. SUS Brasil: Cadernos de Textos - Série B. Textos Básicos de Saúde. Brasília: Ministério da Saúde, p. 108-137, 2004.

MERHY, E. E. Em busca da qualidade dos serviços de saúde: os serviços de porta aberta para a saúde e o modelo tecno-assistencial em defesa da vida (ou como aproveitar os ruídos do cotidiano dos serviços de saúde e colegiadamente organizar o processo de trabalho na busca da qualidade das ações de saúde). CECILIO, L.C.O. (Org.). In: Inventando a mudança na saúde. 2 ed. São Paulo: Editora Hucitec, 1997.

MORAIS, Maria João Moreira de. Saberes e Poderes que Só às Mulheres Pertencem. Actas do VIII Congreso Internacional de Estudos Galegos. Mulleres em Galicia. Galicia e os Outros Pobos da Península, p. 477-486, Barcelona, 2007.

MORIN, Edgar. O método III: o conhecimento do conhecimento. Lisboa; Publicações Europa-América, 1996.

NOGUEIRA, Carlos Roberto F. A migração do Sabbat: a presença "estrangeira" das bruxas europeias no imaginário ibérico. Espacio, Tiempo y Forma, Serie IV, H ${ }^{a}$ Moderna, t. V, p. 930., 1992.

PAIM, J. S. Políticas de saúde no Brasil. In: ROUQUAYROL, M. Z.; ALMEIDA, N. Epidemilogia e Saúde. 6 ed, Rio de Janeiro: Medsi, 2003.

PARADISO, S. R. Mulher, bruxas e a literatura inglesa: um caldeirão de contra discurso. Revista Cesumar, v. 16, n. 1, p.189-202, 2011. 
RIBEIRO, Luis Henrique Leandro. Território e Macrossistema de Saúde: os programas de fitoterapia no Sistema Único de Saúde (SUS). 305 f. Tese. Orientador: Prof. Dr. Marcio Antonio Cataia. Instituto de Geociências, Universidade Estadual de Campinas, Campinas, São Paulo, 2015.

ROSÁRIO, Maria do; SÁ, Lenilde Duarte de; KLÜPPEL, Berta Lúcia Pinheiro. Reza e Tecnologia Leve no Diálogo entre os Saberes Científicos e Populares. Cadernos de Pesquisa em Ciência da Religião, n. 23, p. 96-112, 2014.

SANTOS, B. S. Na oficina do sociólogo artesão: aulas 2011-2016. Seleção, revisão e edição Maria Paula Meneses, Carolina Peixoto. São Paulo: Cortez, 2018.

SANTOS, Denilson Lessa dos. Nas Encruzilhadas da Cura: crenças, saberes e diferentes práticas curativas. 230 f. Dissertação. Orientadora: Profa. Dra. Lina Maria Brandão de Aras. Mestrado em História, Universidade Federal da Bahia, Santo Antônio de Jesus, 2005.

SANTOS, Francimário Vitor dos. O ofício das rezadeiras como patrimônio cultural: religiosidade e saberes de cura em Cruzeta, na região do Seridó Potiguar. Revista CPC, São Paulo, n. 8, p. 6-35, 2009.

SILVA, Araci Farias. O papel das rezadeiras como protagonistas de práticas simbólicas culturais. Revista Espaço Acadêmico. Edição Especial, v. 21, p. 31-43, ago., 2021.

STANCIK, Marco Antonio. Medicina e Saúde Pública no Brasil: dos pajés e físicos aos homens de Ciência do século XX. Revista Esboços, v. 16, n. 21, p. 111-136, 2009.

THEOTONIO, Andrea Carla Rodrigues. Práticas de Rezas: oralidade e cultura no cotidiano das rezadeiras, p. 1-7, 2011.

VASCONCELOS, C. P.; PASCHE, D. F. O Sistema Único de Saúde. In: CAMPOS, G. W. S. Tratado de Saúde Coletiva. São Paulo: Hucitec, 2006.

ZORDAN, Paola Basso Menna Barreto. Bruxas: figuras de poder. Revista Estudos Feministas, v.13, n. 2, p. 331-341, 2005. 